\title{
The influence of heat treatment and resulting microstructures on the thermophysical properties of martensitic steels
}

\author{
Jens Wilzer • Fabian Lüdtke • Sebastian Weber • \\ Werner Theisen
}

Received: 17 June 2013/Accepted: 9 August 2013/Published online: 23 August 2013

(c) The Author(s) 2013. This article is published with open access at Springerlink.com

\begin{abstract}
This research study investigates the influence of heat treatment on the thermal conductivities of three different tool steels at room temperature. The results reveal not only that tempering plays a decisive role in their thermophysical properties, but also that the changes in thermal conductivity due to heat treatment are dependent on the degree of alloying. Isobaric heat capacities $\mathrm{c}_{p}$ are found to be less dependent on heat treatment than thermal diffusivities $a$. The results are discussed with respect to the resulting microstructures and, for high-tempered conditions, under consideration of Calphad calculations. The results are relevant for the thermal design of tools, in particular, for tailored tempering of tools used for press hardening.
\end{abstract}

\section{Introduction}

Tool steels with a microstructure of tempered $\alpha^{\prime}$-martensite are used in a variety of applications, for instance hot extrusion, polymer processing, press hardening, and die casting [1-4]. In addition to wear resistance and mechanical properties such as strength, ductility, and toughness, several thermophysical properties are relevant for tool design. One such property is thermal conductivity, which plays a major role in thermal fatigue and is a key factor in tool life. A higher thermal conductivity reduces temperature gradients at the surface of a tool, for instance, during die casting, and thus the stress amplitude induced by thermal cycling $[5,6]$. In the context of press hardening, the dominant reason for degradation is not thermal fatigue,

J. Wilzer $(\bowtie) \cdot$ F. Lüdtke $\cdot$ S. Weber $\cdot$ W. Theisen

Lehrstuhl Werkstofftechnik, Ruhr-Universität Bochum,

Universitätsstraße 150, 44801 Bochum, Germany

e-mail: wilzer@wtech.rub.de but abrasive wear of the tool surface and sticking of workpiece/coating material [7-9]. However, a high thermal conductivity is also beneficial for press hardening as it determines the cooling rate of a metal blank from the austenitization temperature and thereby directly influences cycle time and productivity $[3,10]$. In contrast, low thermal conductivities are sometimes beneficial for polymer processing to prevent the polymer mass from premature solidification in the tool $[11,12]$. Finally, the design of a tool steel has to consider all technological aspects such as hardness, hardenability, wear resistance, and corrosion resistance together with the thermophysical properties.

Unfortunately, data in the existing literature on thermal conductivities of tool steels are scarce, in particular, with respect to data that also consider the heat-treatment condition, precise chemical composition, and microstructure of the steels. Numerous high-quality studies were published during the 1950 and 1960s, which dealt with the thermophysical properties of pure iron [13-15]. Thermal conductivities of low- and high-alloy steels are also found in the literature, but limited to either only for one occasional heattreatment condition [16-18] or without any information on heat treatment [19-21]. Likewise, technical datasheets of steel producers often provide only one value of thermal conductivity for a steel without mentioning the heat-treatment condition under which this value was determined.

Therefore, the motivation for this study was the need to quantify the effect of heat treatment on certain thermophysical properties, including the thermal conductivity, of three selected tool steels. Nonalloyed grade C45 and two steels primarily used for polymer processing, $40 \mathrm{CrMnMo} 7$ and $\mathrm{X} 42 \mathrm{Cr} 13$, are investigated. Special consideration is given to the initial microstructural state to rule out multiphase effects. The steels are investigated in the as-quenched and deep cryogenically treated state as well as after 
tempering up to a maximum temperature of $600{ }^{\circ} \mathrm{C}$. Changes in the thermophysical properties are then related to microstructural changes and discussed with respect to Calphad calculations of the thermodynamic equilibrium. The results can be generalized for heat-treatable $\alpha^{\prime}$-martensitic steels at room temperature and are used to draw conclusions concerning tool steel design and tailored tempering of tools.

\section{Experimental}

Materials and heat treatment

Three different heat-treatable steels provided by WST Center $\mathrm{GmbH} \& \mathrm{Co} \mathrm{KG}$ were investigated in this study: nonalloyed steel C45, low-alloyed steel 40CrMnMo7, and high-alloyed steel X42C13. Their chemical compositions were determined by optical spark emission spectrometry, and the results are listed in Table 1.

While the carbon levels are similar in all three grades, the concentrations of chromium and manganese, in particular, differ significantly. In addition, the silicon concentrations are less than $0.3 \mathrm{wt} \%$ in $\mathrm{C} 45$ and 40CrMnMo7, whereas $\mathrm{X} 42 \mathrm{Cr} 13$ contains almost $0.5 \mathrm{wt} \%$ of this element. Round cylinders with a diameter of $10 \mathrm{~mm}$ and a length of $35 \mathrm{~mm}$ were machined out of the as-delivered material. Specimens of $\mathrm{X} 42 \mathrm{Cr} 13$ contained local segregations in the as-delivered condition, which is typical for this kind of plastic mold steel [22]. To obtain a fully martensitic microstructure free of inhomogeneities, steel $\mathrm{X} 42 \mathrm{Cr} 13$ was diffusion-annealed at $1200{ }^{\circ} \mathrm{C}$ for $12 \mathrm{~h}$ in a vacuum furnace followed by furnace cooling and an additional normalization treatment at $880^{\circ} \mathrm{C}$. Subsequently, the specimens were austenitized for $1 \mathrm{~h}$ at $1120{ }^{\circ} \mathrm{C}$ quenched in ice water, and then subjected to a deep cryogenic treatment for $24 \mathrm{~h}$ in liquid nitrogen. Deep cryogenic treatment was performed to remove any remaining retained austenite that could falsify the thermal conductivity measurements. Finally, the specimens were tempered at 200, 450 (peak-aged), or 600 ${ }^{\circ} \mathrm{C}$ for $2 \mathrm{~h}$ at each temperature, followed by air cooling. The heat treatments of $\mathrm{C} 45$ and 40CrMnMo7 consisted of austenitization for $1 \mathrm{~h}$ at $850{ }^{\circ} \mathrm{C}$ in a vertical vacuum furnace followed by quenching in ice water and deep cryogenic treatment in liquid nitrogen for $24 \mathrm{~h}$. In addition to the as-quenched condition, tempering with a dwell time of $2 \mathrm{~h}$ was performed at 200,400 , or $600^{\circ} \mathrm{C}$, followed by air cooling.

\section{Microstructural investigations}

For microstructural investigations, specimens with a thickness of $3 \mathrm{~mm}$ were cut perpendicular to the rolling direction and prepared according to standard metallographic methods. These specimens that had already been tempered at 400,450 , or $600{ }^{\circ} \mathrm{C}$ were embedded in an electrically conducting resin at an elevated temperature of $180{ }^{\circ} \mathrm{C}$. Specimens in the as-quenched and in the lowtempered condition were embedded in a nonelectrically conducting resin at room temperature to avoid tempering effects arising from embedding. After grinding and polishing, the specimens were etched either in $3 \%$ nitric acid (Nital; used for C45 and 40CrMnMo7) or a mixture of distilled water, hydrochloric acid, nitric acid, and "Vogels Sparbeize (1-methoxy-2-propanol; isotridecanol; thiocarbamide)" (V2A; used for X42Cr13). Microscopic investigations were performed by scanning electron microscopy using a field emission electron microscope equipped with an in-lens secondary electron detector to make use of the high lateral resolution.

The Vickers hardness of the steels in all heat-treatment conditions was measured according to DIN EN ISO 6507-1 with a load of 294.1 N (HV30). At least two specimens of each condition were measured, and at least five indentations were analyzed on each specimen. In addition, the tempering chart of steel $\mathrm{X} 42 \mathrm{Cr} 13$ was determined in the temperature range, i.e., from room temperature to $600{ }^{\circ} \mathrm{C}$.

\section{Equilibrium calculations}

Calculations of the thermodynamic equilibria were performed using the Calphad software ThermoCalc version $\mathrm{S}$ together with the database TCFe6.2 for iron-based systems [23]. The chemical compositions given in Table 1 were used except for the alloying elements sulfur and phosphorus. On the basis of these calculations, austenitizing temperatures leading to a carbide-free, fully austenitic condition, and equilibrium phase fractions and compositions for a

Table 1 Chemical compositions of the investigated heat-treatable steels determined by optical spark emission spectrometry; values in mass $\%$ with iron being the dependent substitutional element

\begin{tabular}{llllllllll}
\hline & $\mathrm{C}$ & $\mathrm{Cr}$ & $\mathrm{Mn}$ & $\mathrm{Si}$ & $\mathrm{Ni}$ & $\mathrm{Mo}$ & $\mathrm{Cu}$ & $\mathrm{P}$ & $\mathrm{S}$ \\
\hline C45 & 0.463 & 0.178 & 0.661 & 0.289 & 0.114 & 0.021 & 0.167 & 0.116 & 0.025 \\
40CrMnMo7 & 0.375 & 1.706 & 1.416 & 0.217 & 0.061 & 0.161 & 0.048 & 0.009 & 0.001 \\
X42Cr13 & 0.409 & 12.880 & 0.338 & 0.486 & 0.175 & 0.032 & 0.096 & 0.011 & 0.001 \\
\hline
\end{tabular}


tempering temperature of $600{ }^{\circ} \mathrm{C}$ were calculated. In addition, metastable ferrite- $\mathrm{Fe}_{3} \mathrm{C}$ equilibria were calculated for steels $40 \mathrm{CrMnMo} 7$ and $\mathrm{X} 42 \mathrm{Cr} 13$ at a temperature of $600{ }^{\circ} \mathrm{C}$.

\section{Measurement of thermal conductivities}

In this study, the thermal conductivity was measured using the dynamic, indirect method. This implies determination of the thermal diffusivity $a$, the isobaric heat capacity $\mathrm{c}_{p}$, and the density $\rho$.

Densities were measured according to the Archimedes principle using a high-precision laboratory balance. Specimen weights were determined in air and submerged in distilled water. The values from the literature data of the water density at the measurement temperatures were used [24]. The densities of three specimens of each steel were determined in three separate measurements.

Specific isobaric heat capacities were measured by modulated differential scanning calorimetry. The calorimeter was calibrated on the basis of a pure iron specimen after proper baseline correction with empty pans. Specimens with a thickness of $1 \mathrm{~mm}$ and a diameter of $5 \mathrm{~mm}$ were put into one of the two platinum pans placed on Chromel wafers, the empty pan serving as the reference. The temperature program to determine the $\mathrm{c}_{p}$ values at room temperature consisted of a cooling sequence to $-10^{\circ} \mathrm{C}$, with a dwell time of $5 \mathrm{~min}$ at $-10{ }^{\circ} \mathrm{C}$; linear heating up to 230 ${ }^{\circ} \mathrm{C}$ with a basic rate of $10 \mathrm{~K} \mathrm{~min}^{-1}$, and a dwell of $5 \mathrm{~min}$ at $230{ }^{\circ} \mathrm{C}$, followed by cooling down to room temperature. A modulated heating rate with an amplitude of $1 \mathrm{~K}$ and a periodic time of $60 \mathrm{~s}$ was superimposed on the linear basic heating rate. The benefit of the modulated measurement is a higher precision of the measured heat capacities [25, 26]. At least four consecutive measurements were performed for each specimen.

Thermal diffusivities were measured by laser flash analysis. This absolute measuring method does not require a reference material. Round specimens with a length $L$ of $3 \mathrm{~mm}$ and a diameter of $10 \mathrm{~mm}$ were coated with a thin layer of graphite to maximize absorption of the laser radiation. During irradiation of the bottom surface of the specimen, the temperature at its upper surface was monitored continuously with an infrared detector. The time required for the upper surface of the specimen to reach $50 \%$ of the maximum temperature $\left(t_{1 / 2}\right)$ was used to calculate the thermal diffusivity according to Eq. 1 [27].

$a=1.38 \cdot \frac{L^{2}}{\pi^{2} \cdot t_{1 / 2}}$

Of these three quantities - thermal diffusivity, isobaric heat capacity, and density - the thermal conductivity $\lambda$ can be calculated according to Eq. $2[28,29]$. $\lambda=a \cdot c_{p} \cdot \rho$

\section{Results and discussion}

Equilibrium calculations

The calculated phase diagrams of the three steels investigated in this study are shown in Fig. 1. Austenitizing temperatures are denoted by a dot that indicates the fully austenitic equilibrium state for the chosen temperatures of 850 and $1120^{\circ} \mathrm{C}$, respectively.

In the quenched and deep cryogenically treated conditions, martensitic microstructures free of carbide precipitates confirm this result (Figs. 2a, 3a, 4a).

The removal of retained austenite by deep cryogenic treatment was proven indirectly by hardness measurements. The hardness of X42Cr13 increased from 655 HV30 after quenching to 720 HV30 after deep cryogenic treatment (Table 2).

In addition, equilibria calculated for a tempering temperature of $600{ }^{\circ} \mathrm{C}$ are given in Table 3. Most important in this context is the composition of the ferrite-representing the tempered $\alpha^{\prime}$-martensite- that is the closest to pure iron for $\mathrm{C} 45$ but contains significant amounts of alloying elements in case of steel X42Cr13.

Investigations by Geller et al. [30] on high-speed steel led to the conclusion that the chemical composition of the martensitic matrix dominates thermal conductivity. Indeed, precipitation of carbides creates new scatter sources that are supposed to lower $\lambda$, but this effect is overcompensated by depletion of alloying elements in the martensitic matrix. This implies that the investigation concentrates on the chemical composition of the martensitic matrix as a function of tempering temperature and overall chemical composition. For the steels investigated here, especially the element chromium is retained in the ferritic matrix and is not fully precipitated as carbide, in particular, in steels $40 \mathrm{CrMnMo} 7$ and $\mathrm{X} 42 \mathrm{Cr} 13$. In general, all alloying elements when added to a pure metal lower the latter's thermal conductivity by introducing scatter sources for phonons and electrons [28, 31].

Terada et al. [21] measured a significant drop in the thermal conductivity of pure iron for several alloying elements with an increasing impact caused by elements belonging to one group but with increasing periods. Figure 1 shows the differences in the equilibrium concentration of alloying elements for all three steels in the temperature range from 400 to $700{ }^{\circ} \mathrm{C}$. Here, the summation is in atomic percent, $\mathrm{X} 42 \mathrm{Cr} 13$ shows the highest amount of alloying elements retained in the metallic matrix. Furthermore, increasing temperatures entail an increase in alloying element concentration in the ferritic matrix because of the higher solubility of the carbides. These equilibrium calculations do not represent the real 

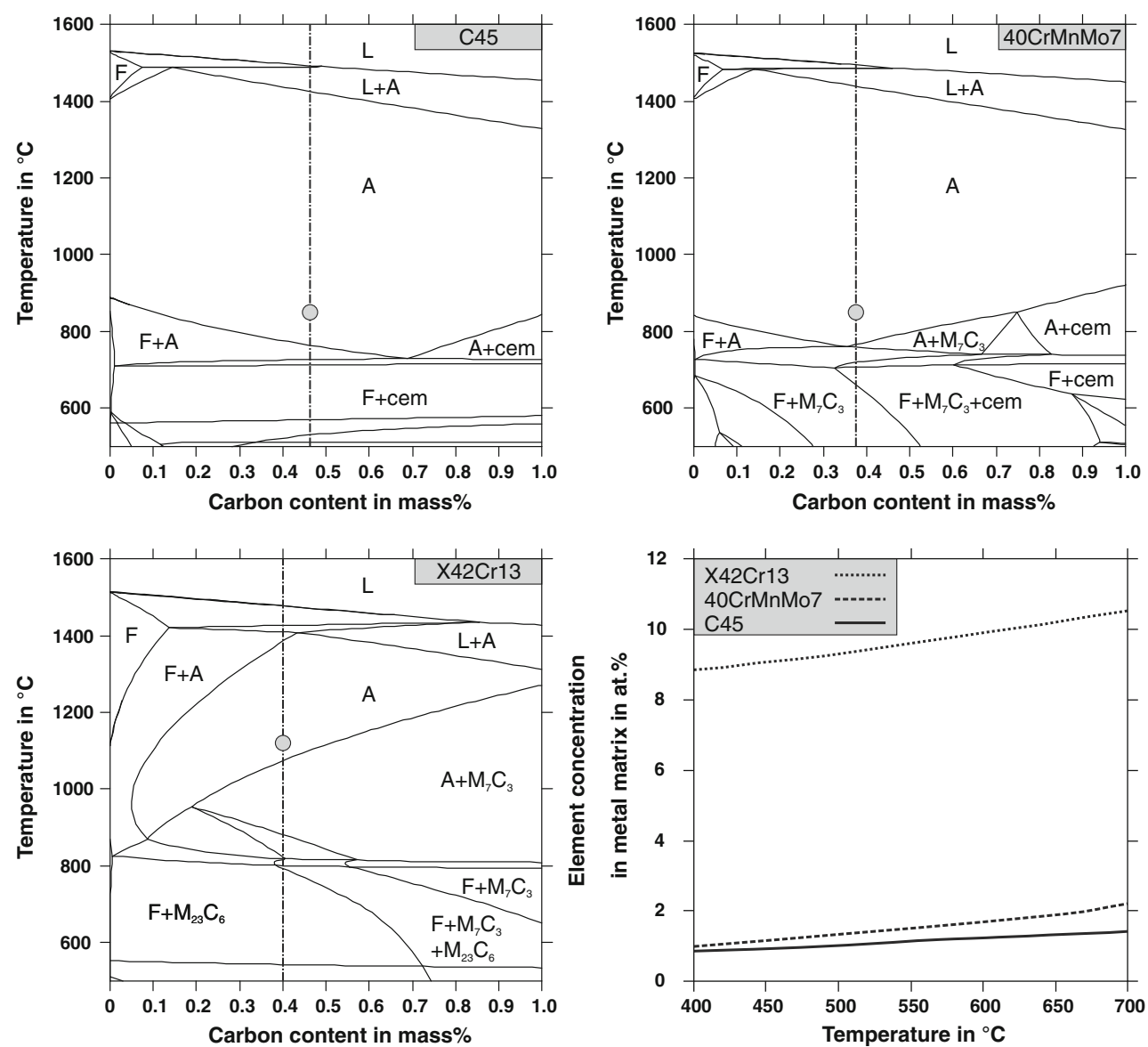

Fig. 1 Calculated phase diagrams including steels $\mathrm{C} 45,40 \mathrm{CrMnMo} 7$, and $\mathrm{X} 42 \mathrm{Cr} 13$. Calculated equilibrium element concentrations (in at.\%) within the metallic matrix for temperatures ranging from 400 to $700{ }^{\circ} \mathrm{C}$

microstructural condition; however, they have several implications with respect to the thermal conductivity.

\section{Quenched conditions}

Thermal conductivity is well known to be strongly dependent on impurities and microstructural imperfections $[16,28,32]$. Both aspects are modified by heat treatment and thus a measurable impact on thermal conductivity of alloyed martensitic steels can be expected. Figure 5 and Table 4 show the measured thermal conductivities of the three steels in the four heat-treatment conditions.

After hardening and deep cryogenic treatment, values ranging between 15 and $35 \mathrm{~W} \mathrm{~m}^{-1} \mathrm{~K}^{-1}$ were determined. For this heat-treatment condition, all alloying elements (Table 1) are present in solid solution in the fully $\alpha^{\prime}$-martensitic matrix. Differences in the thermal conductivities can thus be directly related to overall concentrations of alloying elements in a single-phase microstructure. The higher the total concentration of alloying elements, the lower the thermal conductivity. In particular, steel $\mathrm{X} 42 \mathrm{Cr} 13$ reveals a value of only $15.7 \mathrm{~W} \mathrm{~m}^{-1} \mathrm{~K}^{-1}$ as a result of a high alloy concentration of chromium and silicon. In contrast, the value of nonalloyed steel C45 is about $20 \mathrm{~W} \mathrm{~m}^{-1} \mathrm{~K}^{-1}$ higher, although it is significantly lower than the value for pure iron of about $80 \mathrm{~W} \mathrm{~m}^{-1} \mathrm{~K}^{-1}$ [14]. The difference between the thermal conductivities of pure iron and the nonalloyed steel $\mathrm{C} 45$ is related at least to two effects. First, C45 is fully martensitic in the quenched condition and is thus characterized by a high dislocation density. Second, it contains about 2 mass\% of alloying elements dissolved in the martensitic matrix, even though it is a nonalloyed steel. Both effects, the high dislocation density due to a martensitic microstructure and the alloying elements acting as impurities, are known to reduce thermal conductivity [28, 31, 33]. In particular, Terada et al. [21] measured a reducing influence of the element chromium on the thermal conductivity of ferritic iron. This effect was also reported by Geller et al. [30] for high-speed steels with different chromium contents. In the context of the results shown here (Fig. 5; Table 4), this finding explains the order of alloys with respect to $\lambda: \mathrm{X} 42 \mathrm{Cr} 13$ with a high level of dissolved chromium exhibiting the lowest conductivity followed by $40 \mathrm{CrMnMo} 7$, and C45. 

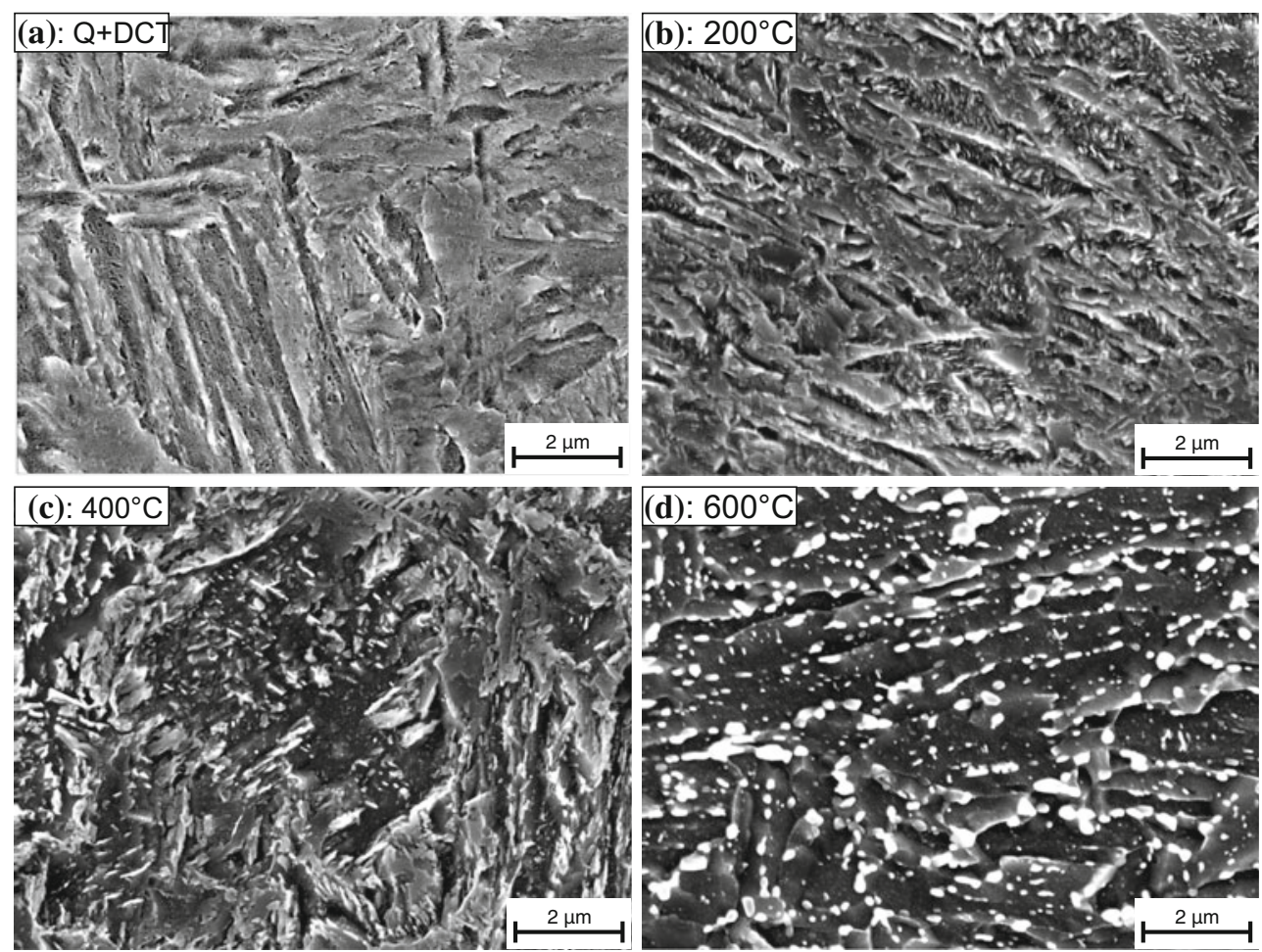

Fig. 2 Microstructure of steel C45 after quenching and deep cryogenic treatment (Q+DCT) and additional tempering at 200 , 400 , or $600{ }^{\circ} \mathrm{C}$
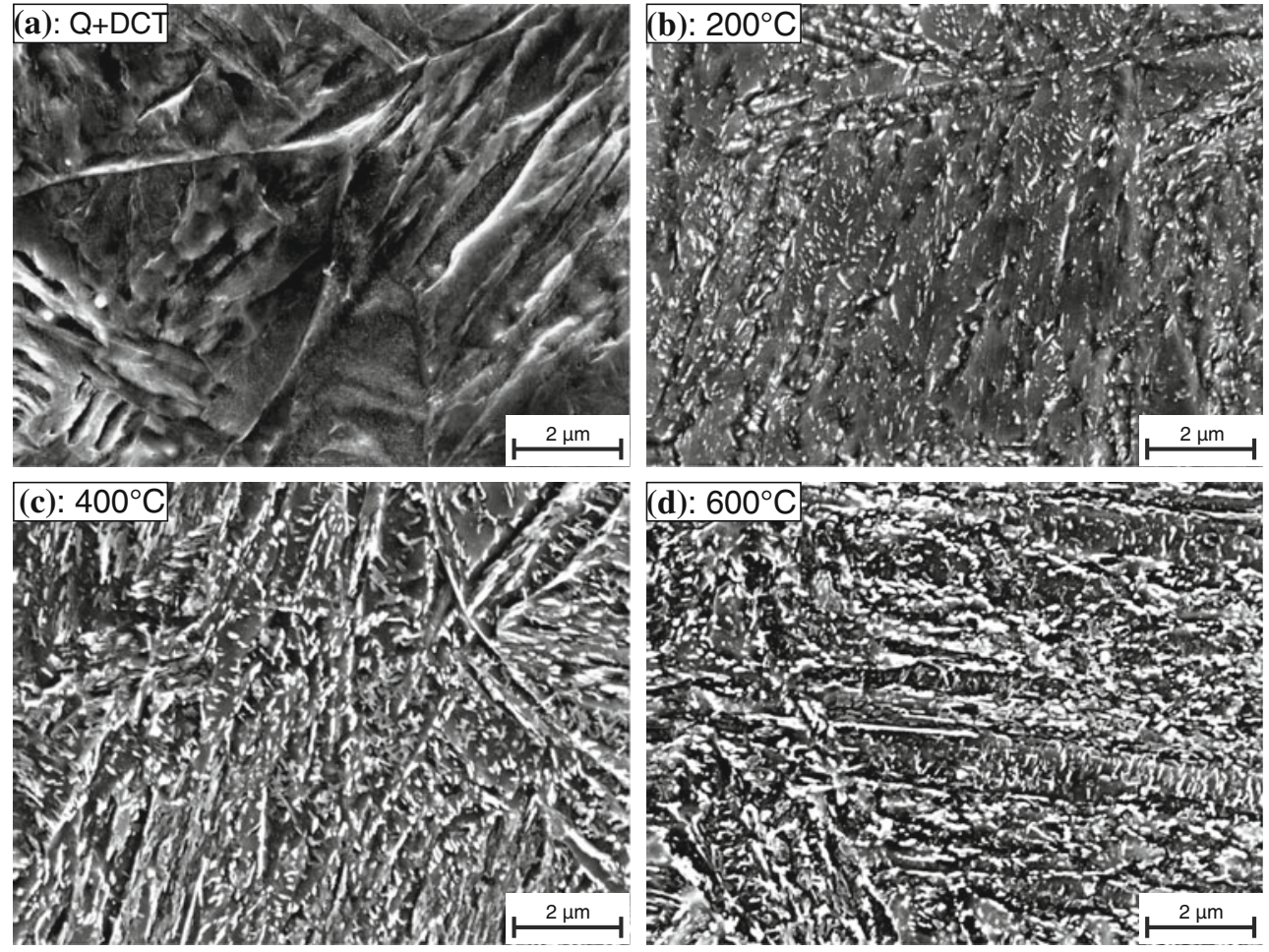

Fig. 3 Microstructure of steel $40 \mathrm{CrMnMo} 7$ after quenching and deep cryogenic treatment (Q+DCT) and additional tempering at 200, 400, or $600{ }^{\circ} \mathrm{C}$ 

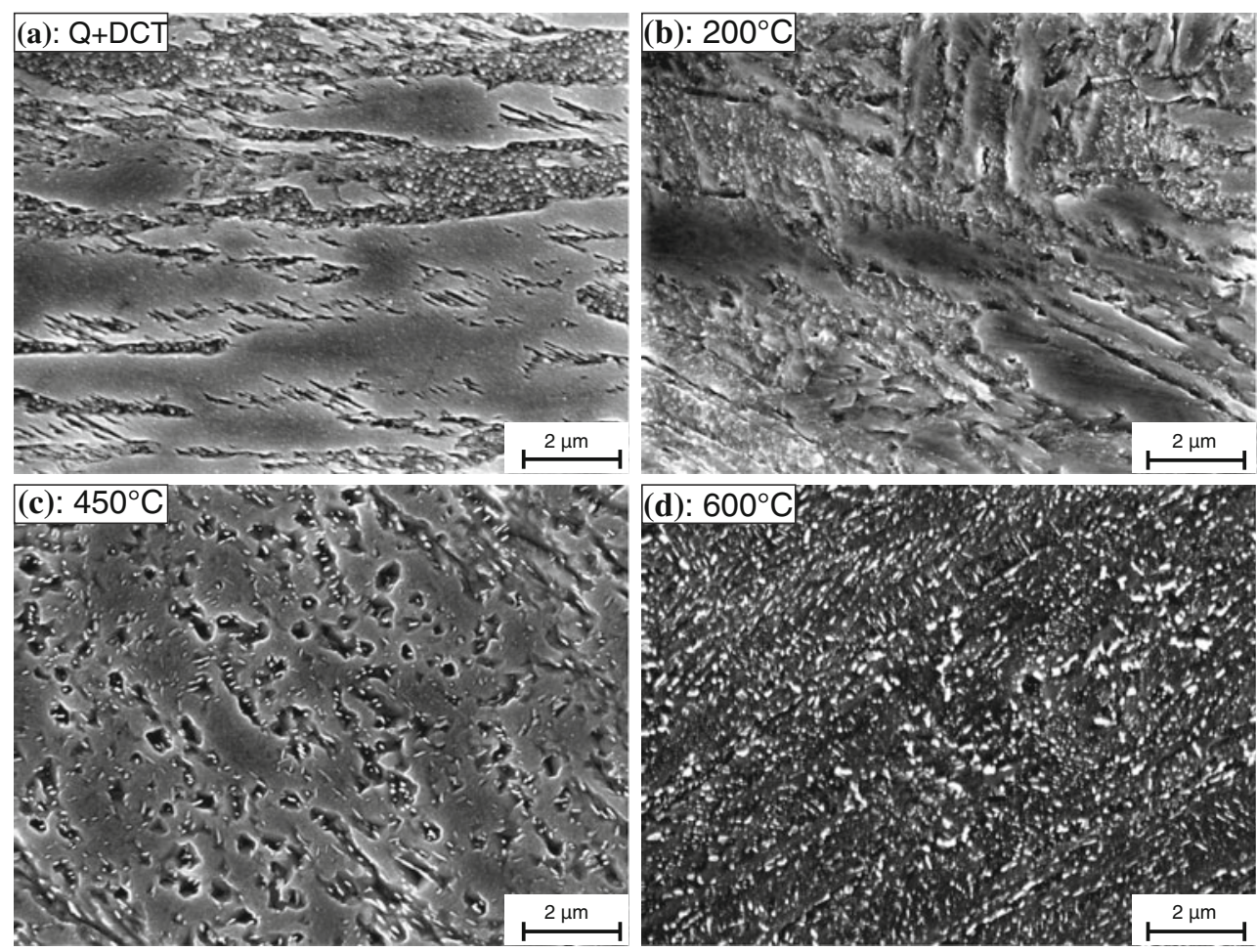

Fig. 4 Microstructure of steel X42Cr13 after quenching and deep cryogenic treatment (Q+DCT) and additional tempering at 200, 450, or 600 ${ }^{\circ} \mathrm{C}$

Table 2 Vickers hardness (HV30) after quenching (Q), quenching plus deep cryogenic treatment $(\mathrm{Q}+\mathrm{DCT})$, and after tempering for $2 \mathrm{~h}$ at different temperatures

\begin{tabular}{llll}
\hline Heat-treatment condition & $\mathrm{C} 45$ & 40CrMnMo7 & X42Cr13 \\
\hline $\mathrm{Q}$ & - & - & $655 \pm 12$ \\
$\mathrm{Q}+\mathrm{DCT}$ & $704 \pm 18$ & $692 \pm 9$ & $720 \pm 9$ \\
$200{ }^{\circ} \mathrm{C}$ & $584 \pm 9$ & $569 \pm 5$ & $630 \pm 23$ \\
$400{ }^{\circ} \mathrm{C}$ & $399 \pm 5$ & $476 \pm 3$ & $558 \pm 22$ \\
$450{ }^{\circ} \mathrm{C}$ & - & - & $593 \pm 10$ \\
$600{ }^{\circ} \mathrm{C}$ & $255 \pm 3$ & $323 \pm 2$ & $346 \pm 8$ \\
\hline
\end{tabular}

Tempered conditions

Tempering of the fully martensitic microstructures activates diffusion of alloying elements which is almost fully inhibited at room temperature. At low tempering temperatures, only carbon is mobile and the movement of the substitutional atoms can be neglected. While below $100{ }^{\circ} \mathrm{C}$ carbon is able to segregate to defects, at higher temperatures, the formation of the metastable hexagonal $\epsilon$ carbide starts and tetragonal distortion of $\alpha^{\prime}$-martensite is lost [34, 35]. This implies that formation of $\epsilon$ carbide is only dependent on the diffusion of carbon, whereas the concentration of substitutional elements within the carbides equals that of the matrix. In specimens of all steels tempered for $2 \mathrm{~h}$ at $200{ }^{\circ} \mathrm{C}$, the formation of carbides was verified by SEM micrographs (Figs. 2b, 3b, 4b). Hardness is reduced due to a loss of carbon from solid solution (Table 2). For the same reason, thermal conductivity increases by tempering at $200{ }^{\circ} \mathrm{C}$ even though the differences to the quenched condition are rather small (Table 4).

Tempering for $2 \mathrm{~h}$ at $400 / 450{ }^{\circ} \mathrm{C}$ results in a higher impact on the thermal conductivity, in particular for nonalloyed steel $\mathrm{C} 45$. The tempering temperature is high enough to allow formation of the stable $\mathrm{Fe}_{3} \mathrm{C}$ carbide, which can be assumed to form close to the matrix composition of substitutional elements due to their low diffusivity. As all three steels have a comparatively low silicon content, the formation of $\mathrm{Fe}_{3} \mathrm{C}$ is not hindered thermodynamically. Recent investigations by Mesquita et al. [3638 ] revealed the distinct influence of silicon on the precipitation sequence in hot-worked tool steel X38CrMoV5-1 (AISI H11). These authors showed that steels alloyed with 0.3 mass \% silicon and less do indeed primarily form $\mathrm{Fe}_{3} \mathrm{C}$, which is stabilized at higher tempering temperatures of more than $600{ }^{\circ} \mathrm{C}$ by the inward diffusion of alloying elements such as chromium, molybdenum, and vanadium. In contrast, silicon contents of 1 or 2 mass $\%$ inhibit formation of $\mathrm{Fe}_{3} \mathrm{C}$ and result in the direct formation of alloy carbides with different crystal structures at high-tempering temperatures. Thus, in the current investigation, the silicon content is of significant importance, first, because of its negative influence on the thermal conductivity of the 
Table 3 Phase equilibria and their respective chemical compositions (mass $\%$ ) at $T=600{ }^{\circ} \mathrm{C}$; the subscripted $m$ denotes metastable ferrite-Fe ${ }_{3} \mathrm{C}$ equilibria

\begin{tabular}{|c|c|c|c|c|c|c|c|c|}
\hline & $\mathrm{C}$ & $\mathrm{Cr}$ & $\mathrm{Mn}$ & $\mathrm{Si}$ & $\mathrm{Ni}$ & Mo & $\mathrm{Cu}$ & $\mathrm{Fe}$ \\
\hline \multicolumn{9}{|l|}{$\mathrm{C} 45$} \\
\hline Ferrite & 0.004 & 0.030 & 0.286 & 0.310 & 0.120 & 0.014 & 0.179 & 99.057 \\
\hline $\mathrm{M}_{3} \mathrm{C}$ & 6.703 & 2.188 & 5.757 & - & 0.031 & 0.118 & - & 85.203 \\
\hline \multicolumn{9}{|c|}{ 40CrMnMo7 } \\
\hline Ferrite & 0.002 & 0.261 & 0.812 & 0.227 & 0.064 & 0.031 & 0.050 & 98.553 \\
\hline $\mathrm{M}_{7} \mathrm{C}_{3}$ & 8.562 & 33.382 & 14.661 & - & 0.005 & 3.006 & - & 40.384 \\
\hline \multicolumn{9}{|c|}{$40 \mathrm{CrMnMo} 7_{m}$} \\
\hline Ferrite & 0.001 & 0.451 & 0.866 & 0.230 & 0.064 & 0.137 & 0.050 & 98.120 \\
\hline $\mathrm{M}_{3} \mathrm{C}$ & 6.801 & 23.285 & 10.878 & - & 0.005 & 0.567 & - & 58.461 \\
\hline \multicolumn{9}{|l|}{$\mathrm{X} 42 \mathrm{Cr} 13$} \\
\hline Ferrite & - & 7.954 & 0.227 & 0.524 & 0.187 & - & 0.104 & 91.004 \\
\hline $\mathrm{M}_{23} \mathrm{C}_{6}$ & 5.601 & 75.419 & 1.749 & - & 0.018 & 0.427 & - & 16.786 \\
\hline \multicolumn{9}{|l|}{$\mathrm{X} 42 \mathrm{Cr} 13_{m}$} \\
\hline Ferrite & - & 8.681 & 0.327 & 0.516 & 0.184 & 0.033 & 0.102 & 90.016 \\
\hline $\mathrm{M}_{3} \mathrm{C}$ & 7.094 & 81.533 & 0.515 & - & 0.005 & 0.013 & - & 10.840 \\
\hline
\end{tabular}

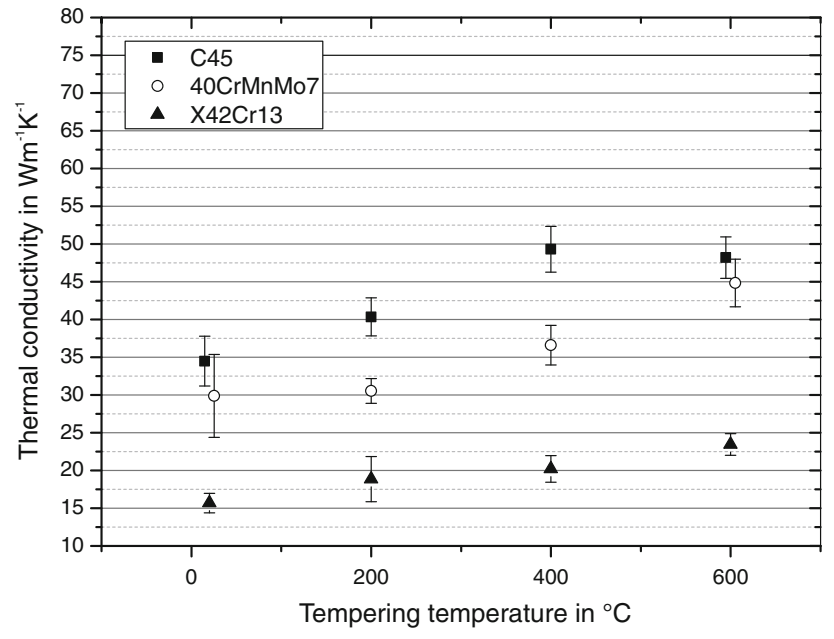

Fig. 5 Thermal conductivities at $T=20{ }^{\circ} \mathrm{C}$ of steels $\mathrm{C} 45$, $40 \mathrm{CrMnMo} 7$, and $\mathrm{X} 42 \mathrm{Cr} 13$ in four different heat-treatment conditions. Maximum scaling of the ordinate corresponds to the thermal conductivity of pure iron of about $80 \mathrm{~W} \mathrm{~m}^{-1} \mathrm{~K}^{-1}$

Table 4 Thermal conductivities $\lambda$ of steels C45, 40CrMnMo7, and $\mathrm{X} 42 \mathrm{Cr} 13$ measured at $T=20{ }^{\circ} \mathrm{C}$ for different heat-treatment conditions

\begin{tabular}{llll}
\hline$\lambda$ in $\mathrm{W} \mathrm{m}^{-1} \mathrm{~K}^{-1}$ & $\mathrm{C} 45$ & $40 \mathrm{CrMnMo} 7$ & $\mathrm{X} 42 \mathrm{Cr} 13$ \\
\hline $\mathrm{Q}+\mathrm{DCT}$ & $34.5 \pm 3.3$ & $30.0 \pm 5.5$ & $5.7 \pm 1.3$ \\
$200{ }^{\circ} \mathrm{C}$ & $40.3 \pm 2.5$ & $30.5 \pm 1.6$ & $18.9 \pm 3.0$ \\
$400{ }^{\circ} \mathrm{C}$ & $49.3 \pm 3.0$ & $36.6 \pm 2.6$ & - \\
$450{ }^{\circ} \mathrm{C}$ & - & - & $20.2 \pm 1.8$ \\
$600{ }^{\circ} \mathrm{C}$ & $48.2 \pm 2.8$ & $44.8 \pm 3.2$ & $23.4 \pm 1.4$ \\
\hline
\end{tabular}

martensitic matrix and, second, because of its impact on the precipitation sequence. Of the steels investigated here, C45 and 40CrMnMo7 contain less than 0.3 mass $\%$ silicon, whereas $\mathrm{X} 42 \mathrm{Cr} 13$ is alloyed with 0.49 mass\%. In all microstructures, carbide formation was detected after tempering at 200 and $400{ }^{\circ} \mathrm{C}$. This leads to the conclusion that $\mathrm{Fe}_{3} \mathrm{C}$ is present, at least after tempering at $400{ }^{\circ} \mathrm{C}$. With the assumption of negligible diffusion of substitutional elements - in particular within the carbides-in the first stages of $\mathrm{Fe}_{3} \mathrm{C}$ formation, a paraequilibrium state is reached. It is characterized by a martensitic matrix almost fully depleted in carbon, but still having the initial chemical composition with respect to substitutional elements. The difference in thermal conductivity between the conditions tempered at 200 and $400{ }^{\circ} \mathrm{C}$ can thus be assigned primarily to depletion of carbon in the martensitic matrix and the onset of its recovery.

Tempering for $2 \mathrm{~h}$ at $600{ }^{\circ} \mathrm{C}$ involves diffusion of substitutional elements. $\mathrm{As} \mathrm{Fe}_{3} \mathrm{C}$ is the equilibrium carbide of steel $\mathrm{C} 45$ at this temperature (Fig. 1), a change in the crystallographic structure of the precipitated carbides is not likely to occur. Instead, thermodynamic equilibrium is achieved by inward diffusion of alloying elements into the $\mathrm{Fe}_{3} \mathrm{C}$ that originally formed with the composition of the martensitic matrix. A Comparison of the full chemical composition of $\mathrm{C} 45$ in Table 1 with the equilibrium composition of the ferrite in Table 3 reveals that only chromium and manganese are depleted in the martensitic matrix due to diffusion into $\mathrm{Fe}_{3} \mathrm{C}$. In contrast, the equilibrium carbides of steels $40 \mathrm{CrMnMo} 7$ and $\mathrm{X} 42 \mathrm{Cr} 13$ at the same temperature are $\mathrm{M}_{7} \mathrm{C}_{3}$ and $\mathrm{M}_{23} \mathrm{C}_{6}$, respectively, according 
to the Calphad calculations. To reach an equilibrium condition, nucleation and growth of these carbides have to take place parallel to dissolution of $\mathrm{Fe}_{3} \mathrm{C}$. Linking this information with the experimental values of the thermal conductivity, the distinct difference observed between $\mathrm{C} 45$ and the two alloyed grades can be explained. C45 does not show a significant difference in $\lambda$ when comparing the heat-treatment conditions of 400 and $600{ }^{\circ} \mathrm{C}$. This saturation is due to full precipitation of carbon in the form of $\mathrm{Fe}_{3} \mathrm{C}$ that is already close to its equilibrium composition due to a low overall alloy concentration. The $\lambda$ values of the other two steels show further increments with tempering temperature because precipitation of carbides and diffusion of alloying elements into them are still ongoing. Even though carbides precipitate, which represent additional imperfections and introduce interfacial effects, it is well known that with increasing tempering temperature the amount of interfacial barriers decreases because of carbide coarsening. Therefore, it can be assumed that the thermal conductivity of all three grades is primarily determined by the matrix composition of the tempered martensite. Taking a look at the equilibrium compositions of ferrite given in Table 3, it becomes clear that steel $\mathrm{X} 42 \mathrm{Cr} 13$ must retain a low value of $\lambda$ because of the high levels of alloying elements dissolved in its matrix of tempered martensite, even if thermodynamic equilibrium is reached.

\section{Dominating factors}

Using the indirect method of determining thermal conductivity, it is possible to interpret the separate contributions of density $\rho$, thermal diffusivity $a$, and heat capacity $\mathrm{c}_{p}$ (Table 5). The densities of all three steels increase on tempering because of a reduction of defect density and particularly to the loss of carbon from solid solution. These effects exceed the volumetric gain resulting from precipitation of carbides exhibiting lower densities than the martensitic matrix. The most significant contribution to changes of thermal conductivity arises from the thermal diffusivity. Tempering at $600{ }^{\circ} \mathrm{C}$ increases these values by $35 \%$ (C45), $43 \%$ (40CrMnMo7), and $46 \%$ (X42Cr13) with respect to the quenched conditions. Changes of isobaric heat capacities by tempering $\mathrm{C} 45,40 \mathrm{CrMnMo} 7$, and $\mathrm{X} 42 \mathrm{Cr} 13$ are indifferent. However, $\mathrm{X} 42 \mathrm{Cr} 13$ shows slightly lower heat capacities compared with $\mathrm{C} 45$ and 40CrMnMo7. Thermal diffusivity is thus the dominating factor, whereas the heat capacity and the density are of minor importance, which is in accordance with the literature [28]. In this context, it is important to notice that these findings are only relevant at room temperature, whereas increasing or decreasing the measurement temperatures are known to contribute significantly to changes in heat
Table 5 Densities $\rho$, thermal diffusivities $a$ and isobaric heat capacities $\mathrm{c}_{p}$ of steels $\mathrm{C} 45,40 \mathrm{CrMnMo} 7$, and $\mathrm{X} 42 \mathrm{Cr} 13$ measured at $T=20{ }^{\circ} \mathrm{C}$ for different heat-treatment conditions

\begin{tabular}{clll}
\hline & $\mathrm{C} 45$ & 40CrMnMo7 & $\mathrm{X} 42 \mathrm{Cr} 13$ \\
\hline$\rho\left(\mathrm{g} \mathrm{cm}^{-3}\right)$ & & & \\
$\mathrm{Q}+\mathrm{DCT}$ & $7.77 \pm 0.02$ & $7.78 \pm 0.02$ & $7.66 \pm 0.02$ \\
$200{ }^{\circ} \mathrm{C}$ & $7.78 \pm 0.02$ & $7.78 \pm 0.02$ & $7.68 \pm 0.02$ \\
$400{ }^{\circ} \mathrm{C}$ & $7.84 \pm 0.02$ & $7.81 \pm 0.02$ & - \\
$450{ }^{\circ} \mathrm{C}$ & - & - & $7.69 \pm 0.01$ \\
$600{ }^{\circ} \mathrm{C}$ & $7.82 \pm 0.02$ & $7.80 \pm 0.02$ & $7.69 \pm 0.02$ \\
$a\left(\mathrm{~cm}^{2} \mathrm{~s}-1\right.$ & & & \\
$\mathrm{Q}+\mathrm{DCT}$ & $0.11 \pm 0.004$ & $0.09 \pm 0.002$ & $0.05 \pm 0.001$ \\
$200{ }^{\circ} \mathrm{C}$ & $0.12 \pm 0.003$ & $0.10 \pm 0.003$ & $0.06 \pm 0.003$ \\
$400{ }^{\circ} \mathrm{C}$ & $0.14 \pm 0.006$ & $0.11 \pm 0.006$ & - \\
$450{ }^{\circ} \mathrm{C}$ & - & - & $0.07 \pm 0.002$ \\
$600{ }^{\circ} \mathrm{C}$ & $0.15 \pm 0.006$ & $0.13 \pm 0.005$ & $0.08 \pm 0.003$ \\
$\mathrm{c}_{p}\left(\mathrm{~J} \mathrm{~g}^{-1} \mathrm{~K}\right.$ & & \\
$\mathrm{Q}+\mathrm{DCT}$ & $0.41 \pm 0.04$ & $0.44 \pm 0.08$ & $0.38 \pm 0.03$ \\
$200{ }^{\circ} \mathrm{C}$ & $0.44 \pm 0.03$ & $0.42 \pm 0.002$ & $0.42 \pm 0.07$ \\
$400{ }^{\circ} \mathrm{C}$ & $0,45 \pm 0.02$ & $0.44 \pm 0.02$ & - \\
$450{ }^{\circ} \mathrm{C}$ & - & - & $0.39 \pm 0.03$ \\
$600{ }^{\circ} \mathrm{C}$ & $0.42 \pm 0.02$ & $0.45 \pm 0.03$ & $0.39 \pm 0.02$ \\
\hline
\end{tabular}

capacities particularly those of ferromagnetic materials $[39,40]$.

\section{Tailored tempering}

Tool steels are primarily used to shape materials, for instance metals or polymers. The thermal design of tools directly influences product quality, cycle time, and productivity. Let us assume that the hardness of a tool is the main criterion to be defined. For nonalloyed and lowalloyed steels such as $\mathrm{C} 45$ and $40 \mathrm{CrMnMo} 7$, it becomes clear that an inverse relationship exists between hardness and thermal conductivity (Tables 2,4 ). Thus, a certain hardness for a given chemical composition is directly related to a thermal conductivity. The situation is different for steels that exhibit secondary hardening. Figure 6 shows a schematic drawing of a tempering chart of a secondary hardening steel having three characteristic points indicated for a hardness levels in the range of 540-550 HV (about 52 HRC).

In principle, this hardness level can be obtained by different tempering procedures, each of them related to different thermal conductivities. Low tempering provides low values of $\lambda$, whereas high tempering is related to a high thermal conductivity, as shown in the present study. Industrial practice involves tempering of tool steels either at low temperatures of about $180{ }^{\circ} \mathrm{C}$ or, in case of secondary hardenable grades, at values beyond the peak-aged 


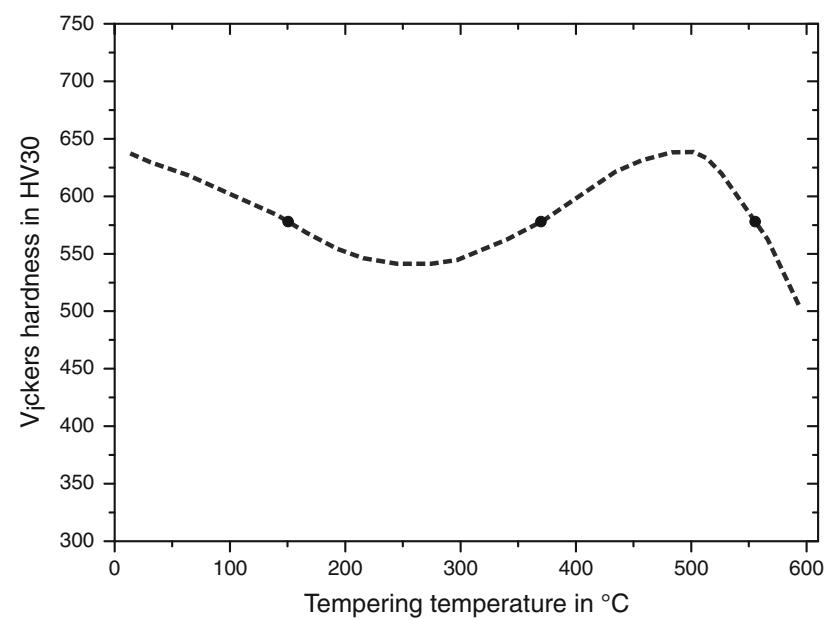

Fig. 6 Schematic drawing of a tempering chart of a secondary hardenable hot-worked tool steel. Conditions of equivalent tempering hardness are indicated by filled dots

condition. However, even these two realistic heat-treatment conditions could serve as a basis for tailored tempering of tools in the context of injection die casting of polymers or press hardening of steel. Local cooling rates influence the resulting material properties. Thus, the surface of a tool could be modified by local heat treatment, e.g., by inductive or laser heating, to obtain regions of higher and lower thermal conductivity. Differences in $\lambda$ of up to $50 \%$ are supposed to be realistic, mainly depending on the tool steel grade.

\section{Summary and outlook}

Room-temperature thermal conductivities $\lambda$ of three martensitic steels were measured after quenching and tempering at 200,400/450, or $600{ }^{\circ} \mathrm{C}$. Values of $\lambda$ are the lowest in the fully martensitic condition and increase on tempering. Changes in $\lambda$ were related to the dislocation density of the $\alpha^{\prime}$-martensite and alloying elements either dissolved in the metal matrix or precipitated as carbides. In fact, the thermal conductivity of heat-treatable martensitic steels was shown to depend strongly on the heat-treatment condition and the resulting microstructure instead of the chemical composition and hardness only. For practical purposes, these differences could be useful for the thermal design of tools using localized tempering.

A detailed investigation of carbides (crystallography, volume fraction, chemistry, and dispersion) and the chemical composition of the metallic matrix by residue analyses is the subject of ongoing study and will be published separately. The effect of temperature on the thermophysical properties of the steels presented in this study will also be investigated to take into account of applications such as die casting of light metals.
Acknowledgement The authors gratefully acknowledge the financial support from the Deutsche Forschungsgemeinschaft (DFG) under support code TH531/13-1.

Open Access This article is distributed under the terms of the Creative Commons Attribution License which permits any use, distribution, and reproduction in any medium, provided the original author(s) and the source are credited.

\section{References}

1. Anderson MJ, McGuire K, Zante RC, Ion WJ, Rosochowski A, Brooks JW (2013) J Mater Process Technol 213(1):111

2. Firrao D, Matteis P, Russo Spena P, Gerosa R (2013) Mater Sci Eng A 559:371

3. Valls I, Casas R, Rodriguez N, Paar U (2010) La Metallurgia Italiana 11-12:23

4. Klobcar D, Tusek J, Taljat B (2008) Mater Sci Eng A 472:198

5. Valls I, Casas B, Rodriguez N (2009) In: Proceedings of the 8th international tooling conference, vol 1, Mainz, Aachen, p 127

6. Hamasaiid A, Valls I, Heid R, Eibisch H (2012) In: Proceedings of the 9th international tooling conference. Verlag "Gutenberghaus", Knittelfeld, p 153

7. Merklein M, Stöhr T, Wieland M (2010) Lightweight Des 3(5):52

8. Karbasian H, Tekkaya AE (2010) J Mater Process Technol 210:2103

9. Hardell J, Prakash B (2008) Tribol Int 41:663

10. Paar U, Valls I (2007) Tagungsband zum 2 Erlanger Workshop Warmblechumformung. Meisenbach, Bamberg, p 73

11. Hill H (2011) Neuartige Metallmatrixverbundwerkstoffe (MMC) zur Standzeiterhöhung Verschleißbeanspruchter Werkzeuge in der polymerverarbeitenden Industrie, Eigenverlag des Lehrstuhls Werkstofftechnik der Ruhr-Universität Bochum, Bochum

12. Liu X-F, Liu F-Q, Yu B-H, Bi C, Zhang B (2012) Adv Mater Res 557-559:2266

13. Kohlhaas R, Kierspe W (1965) Arch Eisenhüttenwesen 36(4):301

14. Richter F, Kohlhaas R (1965) Arch Eisenhüttenwesen 36(11):827

15. Lange KW (1970) Arch Eisenhüttenwesen 41(6):559

16. Bungardt K, Spyra W (1965) Arch Eisenhüttenwesen 36(4):257

17. Richter F (1973) Die wichtigsten physikalischen Eigenschaften von 52 Eisenwerkstoffen: Mitteilung aus dem Forschungsinstitut der Mannesmann AG, Heft 8. Stahleisen, Düsseldorf

18. Richter F (1983) Physikalische Eigenschaften von Stählen und ihre Temperaturabhängigkeit: Polynome und graphische Darstellungen, Heft 10. Stahleisen, Düsseldorf

19. Maurer E (1936) Arch Eisenhüttenwesen 10(4):145

20. Esser H, Eilender W, Pütz E (1938) Arch Eisenhüttenwesen 11(12):619

21. Terada Y, Ohkubo K, Mohri T, Suzuki T (2002) ISIJ Int 42(3):322

22. Mayerhofer J (2012) In: Proceedings of the 9th international tooling conference. Verlag "Gutenberghaus", Knittelfeld, p 325

23. Shi P, Sundmann B (2010) TCC ${ }^{\mathrm{TM}}$ : thermo-Calc $\AA$ software

24. Patterson J, Morris E (1994) Metrologia 31(4):277

25. Thomas L (2001) Am Lab 33(1):26

26. Kozlowski T (2012) Cold Reg Sci Technol 78:896

27. Parker WJ, Jenkins RJ, Butler CP, Abbott GL (1961) J Appl Phys 32(9): 1679

28. Reed RP, Clark AF (1983) Materials at low temperatures. American Society for Metals, Metals Park

29. Tritt T, Weston D (2010) Thermal conductivity. Springer, New York, p 187 
30. Geller Y, Moiseev V, Koltunov A (1963) Metal Sci Heat Treat 5(9):493

31. Wenzl H, Welter J-M (1974) Zeitschrift Metallkunde 65(3):205

32. Uher C (2010) Thermal conductivity. Springer, New York, p 22

33. Madarasz F, Klemens P (1981) Phys Rev B 23(6):2553

34. Berns H, Theisen W (2008) Eisenwerkstoffe: Stahl und Gusseisen, 4th edn. Springer, Berlin

35. Porter D, Easterling KE, Sherif M (2009) Phase transformations in metals and alloys, 3rd edn. CRC Press, Boca Raton
36. Mesquita R, Kestenbach H-J (2011) Mater Sci Eng A 528:4856

37. Mesquita R, Barbosa C, Morales E, Kestenbach H-J (2011) Metall Mater Trans A 42A:461

38. Mesquita R, Kestenbach H-J (2012) Mater Sci Eng A 556:970

39. Braun M, Kohlhaas R (1965) Phys Status Solidi 12(1):429

40. Cezairliyan A, Ho CY, Anderson AC (1988) Specific heat of solids, I-2. Hemisphere Publishing Corporation, New York 